NBER WORKING PAPER SERIES

\title{
RISK AND GLOBAL ECONOMIC ARCHITECTURE: WHY FULL FINANCIAL INTEGRATION MAY BE UNDESIRABLE
}

\author{
Joseph E. Stiglitz \\ Working Paper 15718 \\ http://www.nber.org/papers/w15718 \\ NATIONAL BUREAU OF ECONOMIC RESEARCH \\ 1050 Massachusetts Avenue \\ Cambridge, MA 02138 \\ February 2010
}

The author is indebted to Bruce Greenwald, Mauro Gallegati, Matteo Richiardi, Domenico Delli Gatti, Steffano Battiston, Anton Korinek and Marcus Miller. This paper reports on joint research in the papers in the bibliography, in which these questions are addressed using a variety of different mathematical formulations. I am also indebted to Izzet Yildiz and Jonathan Dingel for invaluable research assistance and to the Ford and Hewlett Foundations for financial support. The views expressed herein are those of the author and do not necessarily reflect the views of the National Bureau of Economic Research.

NBER working papers are circulated for discussion and comment purposes. They have not been peerreviewed or been subject to the review by the NBER Board of Directors that accompanies official NBER publications.

(C) 2010 by Joseph E. Stiglitz. All rights reserved. Short sections of text, not to exceed two paragraphs, may be quoted without explicit permission provided that full credit, including $\odot$ notice, is given to the source. 
Risk and Global Economic Architecture: Why Full Financial Integration May Be Undesirable Joseph E. Stiglitz

NBER Working Paper No. 15718

February 2010

JEL No. F33,F36,G32

\begin{abstract}
$\underline{\text { ABSTRACT }}$
This paper provides a general framework for analyzing the optimal degree and form of financial integration. Full integration is not in general optimal: faced with a choice between two polar regimes, full integration or autarky, autarky may be superior. The intuition is simple: if underlying technologies are not convex, then risk-sharing can lower expected utility. The simplistic models arguing for financial integration typically employed in economics assume convexity; but the world is rife with non-convexities, e.g. associated with bankruptcy. The architecture of the credit market can, for instance, affect the likelihood of a bankruptcy cascade, "contagion," and systemic risk.
\end{abstract}

Joseph E. Stiglitz

Uris Hall, Columbia University

3022 Broadway, Room 814

New York, NY 10027

and NBER

jes322@columbia.edu 
Risk and Global Economic Architecture: Why Full Financial Integration May Be Undesirable Joseph E. Stiglitz

Integration of global financial markets was supposed to lead to greater financial stability, as risks were spread around the world. The financial crisis has thrown doubt on this conclusion. A failure in one part of the global economic system caused a global "meltdown.” The recent crisis has shown that in the absence of appropriate government intervention, privately profitable transactions may lead to systemic risk. This paper provides a general analytic framework within which we can analyze the optimal degree (and form) of financial integration. Within this general framework, full integration is not in general optimal. Indeed, faced with a choice between two polar regimes, full integration or autarky, in the simplified model autarky may be superior.

\section{The Problem.}

Those concerned with designing electric networks have worried about analogous problems. With an integrated electric grid the total capacity required to limit the probability of a blackout to a particular level can be reduced. But a failure in one part of the system can lead to system-wide failure; in the absence of integration, the failure would have been geographically constrained. Well-designed networks have circuit breakers, to prevent the "contagion” of the

\footnotetext{
${ }^{*}$ Columbia University and Brooks World Poverty Institute, Manchester. 3022 Broadway, 814 Uris Hall, New York, NY 10027. jes322@columbia.edu. The author is indebted to Bruce Greenwald, Mauro Gallegati, Matteo Richiardi, Domenico Delli Gatti, Steffano Battiston, Anton Korinek and Marcus Miller. This paper reports on joint research in the papers in the bibliography, in which these questions are addressed using a variety of different mathematical formulations. See also the important work of Andrew G. Haldane (2009) at the Bank of England, and the references cited there. I am also indebted to Izzet Yildiz and Jonathan Dingel for invaluable research assistance and to the Ford and Hewlett Foundations for financial support.
} 
failure of one part of the system to others. Advocates of unbridled liberalization, such as the International Monetary Fund (IMF), have paid little attention to these risks. Indeed, in some quarters, such circuit breakers—such as the temporary imposition of capital controls—have been vehemently opposed, even though worries about contagion were used to justify massive interventions. But diversification and contagion are different sides of the same coin: greater financial integration (especially if not done carefully) increases the risk of adverse contagion in the event of a large negative shock. An analysis of financial integration should weigh the costs with the benefits and begin by asking if there are ways of designing the financial architecture that minimize the downside risk while preserving as much of the upside potential as possible.

\section{A. The General Framework.}

In a series of papers (Bruce Greenwald and Stiglitz, 2003; Domenico Delli Gatti et al., 2006; Mauro Gallegati et al., 2008; Stefano Battiston et al., 2009; Stiglitz, 2010), we have been investigating alternative global architectures. Simple architectures include autarky, where no cross-border capital flows are allowed, and regional arrangements, where no restrictions are imposed on flows within a group of countries but certain restrictions are allowed in the flows between the groups. Restrictions on capital flows in times of crises act as circuit breakers. Alternative architectures are evaluated in terms of "expected utility,” which takes account both mean country performance and variability. We focus in particular on how a shock to one part of the system (one country) can lead to systemic risk through contagion and amplification or adverse impacts might be diminished through risk sharing.

\section{B. First intuition.}

It is well known that, in the absence of a full set of Arrow-Debreu securities or an effective surrogate, the Nash equilibrium will not be efficient. The actions of one unit impose 
externalities on others. Our focus here is on the particular set of externalities associated with risk. The Greenwald-Stiglitz Fundamental Inefficiency Theorem (1986) shows that even with rational expectations, so long as risk markets are incomplete, the market equilibrium will be inefficient. As each market participant makes his investment decision, he affects the price distribution. The current crisis illustrates: as each invested more and more in housing, the price of (say sub-prime) housing would be lower in the event of a state "s" such that they all (or even many) might want to sell. While there is ample evidence that market participants did not act rationally, the Greenwald-Stiglitz theorem shows that such adverse outcomes can happen even had they been rational.

In these second-best situations, imposing restrictions on the set of interactions (relationships) may be welfare enhancing. For instance, trade liberalization between two countries with negatively correlated outputs may reduce price volatility but increase income volatility, so much so that all groups in both countries are worse off (David Newbery and Stiglitz, 1982). In an overlapping generations model, capital market liberalization impairs the extent to which a productivity shock at one time is "shared” with future generations (as increased incomes raise savings and thus future wages) and thus can lower ex ante expected utility (Stiglitz, 2004).

\section{Second intuition.}

But there is an even more compelling reason that global integration may not be desirable. The intuition behind why integration should be desirable was based on "convexity": with convex technologies and concave utility functions, risk sharing is always beneficial. The more globally integrated the world economy, the better risks are “dispersed.” But if technologies are 
not convex, then risk sharing can lower expected utility. While simplistic models typically employed in economics assume convexity, the world is rife with non-convexities.

This is not the place to provide a catalogue of important non-convexities. Information structures, learning processes, $R \& D$, and externalities themselves give rise to a natural set of non-convexities. Bankruptcy introduces a key non-convexity. These in turn may give rise to the financial accelerator (Greenwald and Stiglitz, 2003), which implies that the effect of a shock can be amplified and lead to a process of trend reinforcement. A firm experiencing a negative shock—forcing it closer to the brink of bankruptcy—will have to pay higher interest rates, implying an increased likelihood of a further decline in net worth.

Even without financial market interlinkages, there can be extensive interdependencies through which a shock in one part of the system can be transmitted to others. Liquidity crises are associated with “forced” sales of assets, leading to price declines, adversely affecting any collateral based lending, with obvious macro-economic consequences. Financial linkages, while they may enhance risk sharing, may increase these adverse effects. Bankruptcy cascades (Franklin Allen and Douglas Gale, 2000; Greenwald and Stiglitz, 2003) illustrate the potential adverse effects. The bankruptcy of one firm affects the likelihood of the bankruptcy of those to whom it owes money, its suppliers and those who might depend upon it for supplies; and so actions affecting its likelihood of bankruptcy have adverse effects on others. While contracts may try to control the worst actions (e.g. through bond covenants), these are limited and only partially effective.

Further externalities are generated as a result of information costs and imperfections. If unit $i$ doesn't fully know other units' characteristics - including the relationships (contracts) of 
those with whom it engages in a relationship, including all the relationships with whom those are engaged, ad infinitum — it cannot know the risks of their honoring their contract.

The "architecture" of the credit market can affect the risk that one bankruptcy leads to a sequence of others. If A lends to B, B lends to C, and C lends to D, then a default in D can lead to a bankruptcy cascade. On the other hand, if lending all goes through a sufficiently well capitalized clearing house (a bank), then a default by one borrower is not as likely to lead to a cascade—other things being equal. But other things are never equal: the first structure may have some informational advantages, if A has (say as a byproduct of its trade relationships with B) information about B and its behavior that the bank would not have, or could obtain only at a high cost. ${ }^{1}$ Moreover, the "centralized" lending architecture may be more vulnerable to shocks to the “centers" (illustrated by the global impact of the U.S. credit crisis). Architectures that may better absorb random uncorrelated shocks may perform more poorly in the case of correlated shocks ("targeted attacks"); those that absorb small to medium shocks may perform more poorly in the case of large shocks.

Moreover, in large non-linear systems with complex interactions, even small perturbations can have large consequences; even seemingly small changes in structure (introducing new “connections” or contracts) can alter systemic stability. As our financial system became increasingly intertwined, through complex credit default swaps and other derivatives, too little thought was given to these matters, by the financial wizards that were creating the new products, by the bankers that were marketing them, by the economists that were touting their

\footnotetext{
${ }^{1}$ While credit interlinkages had been studied prior to the crisis (Allen and Gale, 2000; Greenwald and Stiglitz, 2003; Gallegati et al, 2008), such interlinkages were obviously given insufficient attention by regulators and standard models.
} 
virtues, and by the regulators and policymakers who were responsible for ensuring the overall stability of the system.

\section{A Canonical Model.}

\section{A. The Model.}

We now consider a polar case focusing on losses from system failure. Assume that output in country $i$ is a function of a random variable, $S_{i}$, which can be thought of as the stock of available capital. Production is linear in $S$, provided $S$ is greater than some critical number $S^{*}$; when $S \leq S^{*}$, system failure occurs, and a loss of $-C$ occurs. Assume that $S_{i}=-\alpha_{1}$ with probability $p, \alpha_{2}$ with probability $1-p$, such that $p \alpha_{1}=(1-p) \alpha_{2}$, i.e. expected output without bankruptcy is zero. (This is just a normalization.) For simplicity, we assume $S^{*}=0$ and $C<\alpha_{1}$ and $\alpha_{2}<\alpha_{1}$, i.e. $p<.5$ : There is a small probability of “disaster," which is uncorrelated across countries. Prior to liberalization, expected output is $-p C+(1-p) \alpha_{2}=p\left(\alpha_{1}-C\right)$. We now consider integration among $N$ countries. Assume $N=2$. With full liberalization, $p\left(\Sigma S_{i} \leq 0\right)=1-(1-p)^{2}$ i.e. both countries go bankrupt if only one country has a bad outcome; and expected output (per country) is (1-p) $)^{2} \alpha_{2}$ $C\left(1-(1-p)^{2}\right)<-p C+(1-p) \alpha_{2}$.

Liberalization is unambiguously welfare decreasing. A slightly weaker threshold for bankruptcy gives more ambiguous results. Assume bankruptcy occurs if $\Sigma S_{i} / N \leq K<0$. Stiglitz (2010) shows that, for $N=2$, there exists a critical value of $p$ such that if $p \leq p^{*}$ (equivalently, $\alpha_{2}$ $\geq \alpha_{2}{ }^{*}$ ) liberalization is welfare reduced: if disaster occurs rarely but seriously, liberalization is undesirable. The critical $p^{*}$ is defined by $p^{*}=(1-\varsigma)(1-2 \varsigma)$, where $\varsigma \equiv 2 K / \alpha_{1}$. If $\varsigma \geq 1$, then liberalization is always desirable. If $\varsigma=0(K=0)$ — the case discussed earlier-it is never desirable. 
More generally, if there are $N$ countries, there is a critical $p^{*}$ for each $N$ and $K$ such that if $p \leq p^{*}(N, K)$ liberalization is not desirable. ${ }^{2}$ It is obvious, using the law of large numbers, that if $K=0$, as $N$ goes to infinity, crisis (systemic failure) occurs with probability one, so full liberalization is never desirable.

\section{B. Further results.}

The global financial architecture describes the pattern and form of relationships. Stiglitz (2010) uses variants of the canonical model (e.g. where the probability of failure itself may depend on $N$ or where production itself is a concave function of $S$ above the critical threshold) to examine the determinants of the desirability of global financial integration. Consider a simple global financial architecture in which countries are divided into "clubs,” and there is full integration within the club, and no "capital flows” across clubs. Under many parametrizations, there is an optimal size of the club, i.e. neither autarky nor full liberalization is desirable.

The above analysis focused on the polar case-full or no risk sharing. There is a growing consensus that in a financial crisis it may be desirable to restrict capital outflows (as under IMF's program with Iceland). The externalities associated with these capital outflows were sufficiently negative that the benefit of the restriction was viewed to exceed the cost. This is an example of what we call a circuit breaker, a rule that limits the transfer of funds in and out of a country under certain circumstances and therefore limits the extent to which an adverse effect in one country can, through interlinkages, spread around the world. Simulations within a variant of our model show that an appropriately designed circuit breaker can be welfare enhancing.

\footnotetext{
${ }^{2}$ It is straightforward to calculate this critical probability. Define $n^{*}$ as the smallest integer less than $\alpha_{1} / \alpha_{2}$. Assume that $n$ countries have a bad outcome, $N-n$ a good outcome. Then, so long as $n \geq n *$ all countries go into bankruptcy. The probability of this can be derived from the binomial distribution.
} 
Our canonical model also assumed symmetric relationships in which all ties/contracts were identical. In the presence of convexities, such symmetric arrangements often characterize optimal designs. But that is not so in the presence of non-convexities, and there are many alternative architectures. For instance, a set of countries can be tightly linked (a "common financial market”) to each other, but the links among financial markets may be looser. The former is designed to exploit the advantages of risk diversification, the latter to prevent the dangers of contagion. Circuit breakers might be absent in the former but play a large role in the relations among the “common markets.”

\section{Comments on different architectures.}

Our canonical model shows that the risk that a firm or a country’s “capital” would fall below the threshold level could increase with integration. With downward amplification and correlation, the risks of adverse outcomes are even greater. But in fact, as recent and earlier crises illustrate, many firms (countries) undertake similar activities. Indeed, implicit compensation structures often encourage them to do that. It means that they are unlikely to do much worse than others-and with everyone being graded on the curve, that is what matters. It can be shown that there are (from a social perspective) incentives for undertaking excessively correlated strategies. But even without such correlated business strategies, common macroeconomic shocks can induce high levels of correlation, and with correlation the benefits of risk

diversification are reduced and the risks of contagion increased. As we noted earlier, the relative performance of different architectures may depend on the extent of correlation of shocks and behaviors.

This analysis also ignores the diminution of asset quality that results from increasing information imperfections typically associated with more extensive financial market integration, 
and especially securitization. On the other hand, our analysis has omitted the benefits from risk sharing in good states - the production function is linear above $S^{*}$. Still, simulation exercises, combined with intuitions about diminishing returns to risk sharing, suggest that full integration may not be desirable even with reasonable degrees of concavity of the production function.

\section{A. Other applications.}

While our analysis has focused on global financial integration, many of the same issues arise domestically. For instance, if a country has a number of universal banks, following correlated strategies, then episodically, such a country might face systemic crises. By contrast, if a country developed specialized banking institutions, subject to quite different shocks, they may

not all fail contemporaneously. While the real estate banks may fail more often that they would if they were more diversified, the financial system as a whole might fail less frequently, particularly if there were provisions for expansion of sector banks into other areas in times of exigencies. By the same token, financial linkages across firms, e.g. through credit default swaps, may enhance systemic vulnerabilities.

\section{B. Concluding comments.}

This paper, focusing on risk, has just touched the surface of the complexities of optimal financial architectures. Even ignoring issues raised by learning, information asymmetries, and institutional coordination, it has been shown that full integration may be less desirable than previously thought. There is a rich policy and research agenda ahead. 


\section{References}

Allen, Franklin, and Douglas Gale. 2000. “Financial Contagion.” Journal of Political Economy, 108(1): 1-33.

Battiston, Stefano, Domenico Delli Gatti, Mauro Gallegati, Bruce Greenwald, and Joseph E. Stiglitz. 2009. “Liaisons Dangereuses: Increasing Connectivity, Risk Sharing, and Systemic Risk.” Paper presented at the Eastern Economic Association Meetings, New York.

Delli Gatti, Domenico, Mauro Gallegati, Bruce Greenwald, Alberto Russo, and Joseph E.

Stiglitz. 2006. "Business fluctuations in a credit-network economy.” Physica A, 370: 68-74.

Gallegati, Mauro, Bruce Greenwald, Matteo G. Richiardi, and Joseph E. Stiglitz. 2008. “The Asymmetric Effect of Diffusion Processes: Risk Sharing and Contagion.” Global Economy Journal 8(3).

Greenwald, Bruce, and Joseph E. Stiglitz. 1986. “Externalities in Economies with Imperfect Information and Incomplete Markets.” Quarterly Journal of Economics, 101(2): 229-264. . 2003. Towards a New Paradigm of Monetary Economics, Cambridge: Cambridge

University Press.

Haldane, Andrew G. 2009. "Rethinking the Financial Network.” Speech at the Financial Students Association, Amsterdam.

Newbery, David, and Joseph E. Stiglitz. 1984. “Pareto Inferior Trade.” Review of Economic Studies, 51(1):1-12.

Stiglitz, Joseph E. 2004. “Capital-Market Liberalization, Globalization and the IMF,” Oxford Review of Economic Policy, 20(1): 57-71.

_ 2010. “Contagion, liberalization, and the optimal structure of globalization,” Journal of Globalization and Development, forthcoming. 